\title{
A METHOD FOR THE CONTINUOUS MEASUREMENT OF CEREBRAL BLOOD FLOW IN MAN BY MEANS OF RADIOACTIVE KRYPTON $\left(\mathrm{KR}^{79}\right) *$
}

\author{
By BENJAMIN M. LEWIS, $\dagger$ LOUIS SOKOLOFF, RICHARD L. WECHSLER, \\ W. BUDD WENTZ AND SEYMOUR S. KETY \\ (From the Aviation Medical Acceleration Laboratory, U. S. Naval Air Development Center, \\ Johnsville, Pa., the Laboratory of Clinical Science, National Institute of Mental \\ Health, Bethesda, Md., and the Department of Physiology and Pharma- \\ cology, Graduate School of Medicine, Philadelphia, Pa.)
}

(Submitted for publication March 26, 1959; accepted May 15, 1959)

The measurement of cerebral blood flow by means of the nitrous oxide method of Kety and Schmidt (1) or the krypton-85 $\left(\mathrm{Kr}^{85}\right)$ technique of Lassen and Munck (2) requires a steady state of at least ten minutes, for it is not until the end of such a period that the uptake of the gas by the brain can be estimated indirectly from its concentration in cerebral venous blood. These methods are, therefore, not applicable to the study of rapid or transient changes in cerebral blood flow. If, however, a $\gamma$-emitting inert gas such as krypton-79 $\left(\mathrm{Kr}^{79}\right)$ is employed, its uptake by the brain can be followed by direct measurement of the $\gamma$-radiation through the intact skull, thus permitting the continuous measurement of cerebral blood flow during transient or rapid changes before equilibration between brain tissue and cerebral venous blood is achieved.

The description of the development, evaluation and application of such a method is the subject of this report.

\section{METHOD}

\section{Theory}

Like the nitrous oxide method, the $\mathrm{Kr}^{78}$ method is based upon the Fick principle, which can be expressed as follows:

$$
\frac{\mathrm{d} Q_{B}}{d t}=\operatorname{CBF}\left(C_{A}-C_{V}\right) \text {, }
$$

where $d Q_{B} / d t$ is the time rate of change of the quantity of $\mathrm{Kr}^{79}$ in the brain, $\mathrm{CBF}$ is the rate of blood flow through the brain assuming equal arterial inflow and venous outflow, and $C_{A}$ and $C_{V}$ are the arterial and rep-

* Opinions or conclusions contained in this report are those of the authors and are not to be construed as necessarily reflecting the views or endorsements of the Navy Department.

$\dagger$ Present address: Department of Medicine, Wayne State Universitv. College of Medicine, Detroit 7, Mich. resentative cerebral venous $\mathrm{Kr}^{7 \vartheta}$ concentrations, respectively.

Since accurate measurement of instantaneous rates of change like $d Q_{B} / d t$ is difficult, it is preferable to integrate Equation 1 between definite intervals, short enough to keep the resolution time of the method small and to permit the approximation that cerebral blood flow had remained constant during the interval but long enough to allow accurate determinations of the change in quantity of $\mathrm{Kr}^{79}$ in the brain. Thus, in the integrated and transposed form,

$$
\mathrm{CBF}=\frac{\Delta Q_{\mathrm{B}} \mid \begin{array}{l}
\mathrm{t}_{2} \\
\mathrm{t}_{1}
\end{array}}{\int_{\mathrm{t}_{1}}^{\mathrm{t}_{2}}\left(\mathrm{C}_{\mathrm{A}}-\mathrm{C}_{\mathrm{V}}\right) \mathrm{dt}} .
$$

Equation 2 states that the cerebral blood flow rate during a given interval of time is equal to the change in brain $\mathrm{Kr}^{79}$ content divided by the integrated arteriovenous $\mathrm{Kr}^{79}$ concentration difference during the same interval of time. By measuring brain content and arterial and venous concentrations either continuously or repeatedly at fixed successive intervals of time, as, for example, the one minute intervals in these studies, cerebral blood flow can be calculated continuously over successive one minute periods until the rate of change of $Q_{B}$ and/or the arteriovenous difference become too small to be determined reliably. Equation 2 applies during saturation or desaturation of the brain with $\mathrm{Kr}^{70}$. Furthermore, since $Q_{B}$ represents total brain $\mathrm{Kr}^{79}$ content and not concentration in the cerebral tissues, CBF is a measure of the blood flow to the whole brain rather than to a representative fraction of it, as is the case with the nitrous oxide method.

$Q_{B}, C_{A}$, and $C_{V}$ are determined by the counting of the $\gamma$-radiation of the $\mathrm{Kr}^{79}$ and are expressed as counts per minute (cpm) in the brain or cpm per milliliter of blood, respectively. Since the counting rates in brain and blood are determined under different geometric conditions and, indeed, by different counters, counting efficiencies are different for these two types of measurements, and an equivalence factor (F) obtained by counting a standard $\mathrm{Kr}^{78}$ source under the two conditions in a manner to be described below must be included in the numerator of Equation 2. 


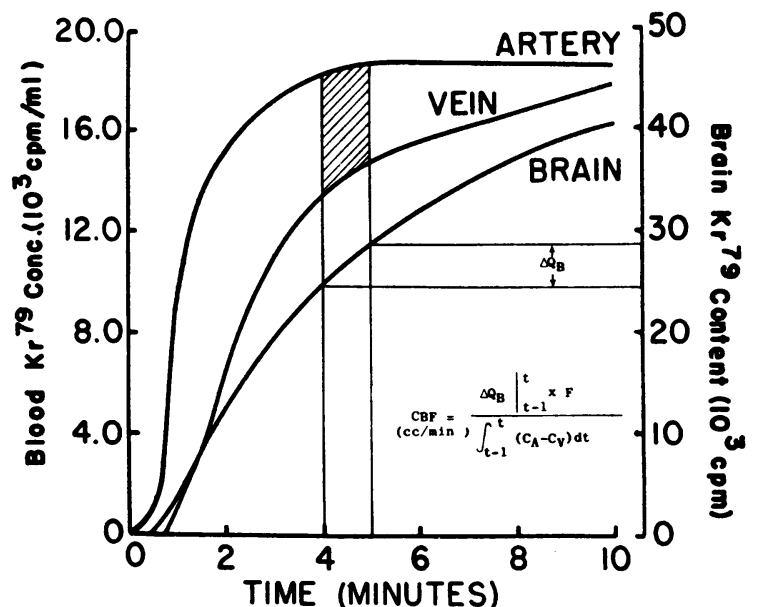

Fig. 1. Typical CURVES For ARTERIAL AND INTERNAL JUGULAR VENOUS $\mathrm{KR}^{79}$ CONCENTRATIONS AND BRAIN $\mathrm{KR}^{\text {t9 }}$ CONTENT DURING SATURATION WITH THE RADIOACTIVE GAS. The formula and the method for the calculation of $\mathrm{CBF}$ during a one minute interval (fifth minute) are illustrated. $\Delta Q_{B}$ during the fifth minute is the numerator of the formula and is obtained as indicated; the shaded area between the arterial and cerebral venous curves represents the integrated arteriovenous difference during the same interval of time, and is the denominator of the formula. $\mathrm{F}$ is a proportionality constant which converts blood and brain counting rates to equivalent units (see text). To obtain continuous minute-to-minute values for cerebral blood flow, the calculation is repeated for each successive one minute interval of time.

The application of this equation to the calculation of cerebral blood flow is illustrated in Figure 1.

Properties, preparation and administration of $K r^{79}$. $\mathrm{Kr}^{78}$ was chosen as the tracer substance for this method because it is a chemically inert gas which diffuses freely across the blood-brain barrier, emits $\gamma$-radiation which permits its direct measurement in brain by means of external counting techniques, and has a suitably short physiological half-life. Its physical half-life is 34 hours (3), and its decay scheme includes $\mathrm{K}$-capture, positron emission, and at least $15 \gamma$-transitions ranging in energy from 44.5 to $833.4 \mathrm{Kev}$ (4). It was produced for these studies by deuteron bombardment of potassium bromide in a cyclotron ${ }^{1}$; the $\mathrm{Kr}^{79}$ formed by the ensuing $\mathrm{Br}-\mathrm{d}-2 \mathrm{n}$ reaction is trapped in the crystal structure of the bromide. Other radioactive isotopes $\left(\mathrm{Br}^{80}\right.$ and $\left.\mathrm{Br}^{82}\right)$ are also formed in the process. The occluded $\mathrm{Kr}^{79}$ is released by solution of the potassium bromide in bromine water in an enclosed atmosphere containing air and a barely measurable volume of inert carrier krypton. The bromine water is then completely distilled into a dry ice-acetone cold trap; the overlying gas is passed

${ }^{1} \mathrm{Kr}^{79}$ was produced for these studies in the Cyclotron Laboratory of the Massachusetts Institute of Technology. through a sodium hyposulfite scrubber to remove any residual radioactive bromine and finally collected in an evacuated $1 \mathrm{~L}$ tonometer. The yield of $\mathrm{Kr}^{78}$ was assayed by measurement of the $\gamma$-radiation from the tonometer at a distance of $100 \mathrm{~cm}$ with an ionization chamber type survey meter which had previously been calibrated with a known $\mathrm{Kr}^{79}$ source. ${ }^{2}$ The quantity of $\mathrm{Kr}^{79}$ obtained in the tonometer generally approximated $5 \mathrm{mc}$.

The $\mathrm{Kr}^{79}$ was administered to the subjects in the inspired air which was prepared by flushing the contents of the tonometer into a spirometer and diluting with room air to a final concentration of $100 \mu \mathrm{c}$ per L. Administration was usually through a non-rebreathing system with collecton of the expired air in a Douglas bag, but in a few cases to be discussed below, rebreathing with $\mathrm{CO}_{2}$ absorption and $\mathrm{O}_{2}$ replacement was employed. Under the conditions of these experiments, the highest radiation dosage is in the lungs and has been calculated to be less than $0.1 \mathrm{rad}(5)$.

Measurement of $\mathrm{Kr}^{79}$ content in brain. The quantity of $\mathrm{Kr}^{79}$ in the brain is measured by means of a scintillation counter precisely located with respect to the brain and carefully shielded to exclude radiation from all bodily areas except the brain and overlying extracerebral tissues. The scintillation probe consists of a cylindrical, thallium-activated sodium iodide crystal, $4 \mathrm{~cm}$ in diameter and $10 \mathrm{~cm}$ in length, a Dumont 6292 photomultiplier tube, and a cathode-follower type pre-amplifier, all enclosed within a light-proof aluminum shield. With the subject in the supine position, the probe is placed laterally with respect to the head so that its proximal end is approximately $25 \mathrm{~cm}$ from the midsagittal plane of the head and its longitudinal axis is directed at the midpoint of the line connecting the opening of the external auditory meatus and the top of the crown (Figure 2). The entire probe is surrounded by a 2 inch thick lead cylinder, 12 inches in diameter (Figure 2). Between the side of the head and the proximal end of the lead cylinder, but flush against both, is a 2 inch thick flat lead plate which is cut in the shape of the contours of the brain as "seen" by the scintillation probe (Figure 2 ). The lead shield was designed to exclude from the probe all $\mathrm{Kr}^{78}$ radiation from the room, body and head except that of the brain and directly overlying extracerebral tissues; its design was determined by experiments with a plastic model of the head containing multiple compartments representing brain, extracerebral tissues, and respiratory passages which could be filled with $\mathrm{Kr}^{7 \theta}$ solutions or gas mixtures as indicated.

The output pulses of the scintillation probe are first amplified (Atomic Instrument Co. Linear Amplifier Model 204-B) and then counted in a decade scaler (Atomic Instrument Co. Model 1070A) equipped with a pulse height discriminator adjusted to the minimum level necessary to exclude all tube noise and other electronic artifacts. Continuous recording of the counting

${ }^{2}$ This $\mathrm{Kr}^{29}$ source was standardized for us by $\mathrm{Dr}$. Sherman Frankel, Department of Physics, University of Pennsylvania. 


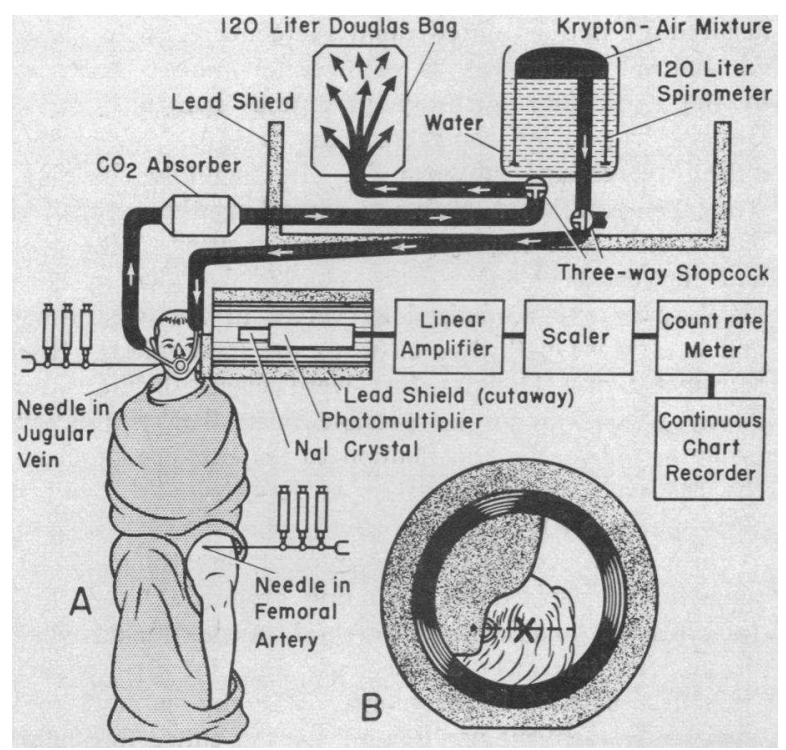

Fig. 2. Diagrammatic Representation of ExPERIMENTAL SETUP. A, overall view of physical arrangement of subject, lead shields and apparatus; $B$, view of head as seen by scintillation counter in lead shield with the $\mathrm{X}$ marking the point at which the longitudinal axis of the scintillation crystal is directed.

rate is achieved by photography of the scaler face and timer or by differentiation of the scaler output by means of a count rate meter, the output of which is recorded on an Esterline-Angus recording milliammeter.

Measurement of $\mathrm{Kr}^{\mathrm{79}}$ concentration in blood. If three complete counting channels are available, it is possible to monitor the arterial and cerebral venous $\mathrm{Kr}^{79}$ concentrations continuously and simultaneously with the counting from the brain. This can be accomplished by the continuous sampling of blood at a constant rate through glass helices fixed in the wells of well-type scintillation counters. In the present studies, however, discrete, timed arterial and cerebral venous blood samples were drawn into oiled, heparinized syringes at intervals as close to one minute as possible, and their $\mathrm{Kr}^{79}$ concentrations were assayed subsequently by measurement of the counting rates in aliquots of each of them transferred consecutively to a single glass helix-scintillation counter system. Each blood sample was mixed by shaking with mercury and introduced into the helix via one of the two-way stopcocks attached by plastic tubing to each opening of the helix. These stopcocks were closed when the system was filled, and by transferring an excess of blood through the helix, anaerobic conditions were maintained for the sample being assayed. The use of the helix also assured a constancy of sample volume and geometric conditions. Between samples the helix was flushed with water, then isopropyl alcohol, and finally dried by a current of air. Sufficient sample counts were collected to yield a coefficient of variation of less than 3 per cent, and corrections were made for background and also for radioactive decay from the time of the head counting procedure.

Determination of the factor $F$. The factor, $F$, described previously in the discussion of the theory, is actually a proportionality constant between the overall brain and blood counting efficiencies and can be defined as follows :

$$
\mathrm{F}=\frac{\mathrm{B}}{\mathrm{S}}
$$

where $B$ equals the counting rate from a given quantity of $\mathrm{Kr}^{\text {78 }}$ in blood counted under the blood counting conditions and $S$ equals the counting rate from the same quantity of $\mathrm{Kr}^{79}$ distributed throughout the brain and counted under the brain counting conditions.

Since S cannot readily be determined in situ, a Plexiglas phantom model of the head was constructed which contained separate "brain," "airway," and "extracerebral" compartments and conformed to average anthropological measurements for adult Caucasian males. The phantom model was utilized in the following manner. A 10 $\mathrm{ml}$ syringe containing $5 \mathrm{ml}$ of an aqueous $\mathrm{Kr}^{79}$ solution was counted at various distances between 20 and $95 \mathrm{~cm}$ from the end of the scintillation crystal employed in the measurement of $\mathrm{Kr}^{79}$ in the brain. The contents of the syringe were than quantitatively transferred into the water-filled "brain" compartment of the Plexiglas model ; the "extracerebral" compartment was filled with $\mathrm{Kr}^{\text {78}}$ free water. Counting rates from the brain model were then measured at various distances from the scintillation crystal which was directed at the same point in the model as in the measurements from the head described previously (Figure 2). The ratio of "brain" to syringe counting rates was thus determined at various distances between the center of each and the end of the probe. It was found not to change systematically between 25 and $95 \mathrm{~cm}$ and to average 0.67 over that range (Figure 3). Linear absorption coefficients for the overall $\gamma$-radiation of $\mathrm{Kr}^{79}$ in water, Plexiglas, brain, and calvarium were also experimentally determined; their values indicated that for the distances involved differences in self-absorption in the model and human head were negligible. It was concluded, therefore, that under the counting conditions described, a given quantity of $\mathrm{Kr}^{79}$ distributed in the brain yields a counting rate equal to 67 per cent of its rate at the same distance when distributed in $5 \mathrm{ml}$ of solution contained in a $10 \mathrm{ml}$ syringe. This information makes possible the determination of $\mathrm{S}$ in Equation 3 and, therefore, also the factor, $\mathrm{F}$.

Since the efficiencies of the scintillation counters may vary from day to day, $F$ must be determined for each experiment. The procedure is as follows. A concentrated solution of $\mathrm{Kr}^{79}$ in blood is made by equilibrating a sample of the subject's blood with a small sample of the undiluted $\mathrm{Kr}^{79}$-air mixture. Five $\mathrm{ml}$ of this solution is drawn into a $10 \mathrm{ml}$ syringe; gas bubbles are carefully expelled, and the syringe is capped. Its contents are referred to in subsequent discussion as the "standard" $\mathrm{Kr}^{79}$ solution. The syringe is placed at pre- 
cisely the same distance from the end of the scintillation crystal as was the midsagittal plane of the head during the cerebral blood flow measurement, and its counting rate is determined under the same conditions and with the identical equipment employed in the measurement of brain $\mathrm{Kr}^{79}$ content. A sample of the standard $\mathrm{Kr}^{79}$ solution is then transferred to the glass helix and counted with the same equipment and in the same manner as the experimental blood samples.

If $\mathrm{N}_{\mathrm{h}}$ and $\mathrm{N}_{\mathrm{s}}$ are the counting rates obtained from the standard solution in the helix and in the syringe, respectively, and $V_{h}$ and $V_{s}$ are the corresponding volumes of the solution in the helix and the syringe, then from Equation 3 and the results of the experiments with the phantom "brain" model,

$$
\mathrm{F}=\frac{\mathrm{B}}{\mathrm{S}}=\frac{\mathrm{N}_{\mathrm{h}} / \mathrm{V}_{\mathrm{h}}}{0.67 \mathrm{~N}_{\mathrm{s}} / \mathrm{V}_{\mathrm{s}}}=\frac{\mathrm{N}_{\mathrm{h}} \mathrm{V}_{\mathrm{s}}}{0.67 \mathrm{~N}_{\mathrm{s}} \mathrm{V}_{\mathrm{h}}}
$$

Since the arterial and cerebral venous concentrations are determined directly in counts per minute per helix volume, the helix volume, $V_{h}$, cancels out when $F$ is introduced into Equation 2.

The final form of the equation from which $\mathrm{CBF}$ is calculated is then as follows:

$$
\mathrm{CBF}=\frac{\left.\Delta Q_{\mathrm{B}}\right|_{\mathrm{t}-1} ^{\mathrm{t}} \times \mathrm{N} \mathrm{N}_{\mathrm{h}} \mathrm{V}_{\mathrm{s}}}{\int_{\mathrm{t}-1}^{\mathrm{t}}\left(\mathrm{C}_{\mathrm{A}^{\prime}}-\mathrm{C}_{\mathrm{v}^{\prime}}\right) \times 0.67 \mathrm{~N}_{\mathrm{s}}}
$$

where $C_{\Delta}{ }^{\prime}$ and $C_{v^{\prime}}$ are the arterial and cerebral venous concentrations in counts per minute per helix volume.

\section{Procedure}

All studies reported here were performed in normal young men in the supine position. Arterial and cerebral venous blood was sampled as previously described (1). After establishment of the sampling systems, the head was carefully placed with respect to the scintillation probe and lead shield as described above.

In all studies $\mathrm{Kr}^{79}$ concentration in the inspired air was adjusted to approximately $100 \mu \mathrm{c}$ per $\mathrm{L}$ by dilution in a $120 \mathrm{~L}$ spirometer with room air or a mixture of 15 per cent $\mathrm{N}_{2} \mathrm{O}, 64$ per cent $\mathrm{N}_{2}$, and 21 per cent $\mathrm{O}_{2}$. The nitrous oxide mixture was employed in several studies in which cerebral blood flow was measured simultaneously by the nitrous oxide technique (1) for the purpose of comparison with the $\mathrm{Kr}^{79}$ method. Administration was usually through a non-rebreathing respiratory system. A rebreathing system was used only when the $\mathrm{Kr}^{79}$ was insufficient to dilute to the specified concentration and volume necessary to sustain respiration for at least 10 minutes. Cerebral blood flow was then measured only during the desaturation period following 10 minutes of rebreathing of the inspired gas mixture. During the rebreathing, $\mathrm{CO}_{2}$ was removed by a barolime absorber in the expiratory circuit, and oxygen was fed into the spirometer to maintain constant the $\mathrm{O}$. tension monitored by a Pauling oxygen analyzer in the inspiratory pathway. A three-way stopcock in the inspired air line permitted rapid switching between room air and spirometer gas as required; a similar stopcock in the expiratory pathway permitted switching to a Douglas bag during non-rebreathing or to the spirometer during rebreathing (Figure 2). To facilitate shielding from the scintillation probe, a rubber mouthpiece rather than a mask was employed for administration of the gas, and the nasal passages were blocked by a nose clip. Dead space was minimized by valves in the inspiratory and expiratory pathways close to the mouthpiece. The spirometer and Douglas bag were placed behind lead $\mathrm{X}$-ray shields as far as possible from the scintillation probe to reduce the contribution to the background from the relatively large quantities of $\mathrm{Kr}^{79}$ contained within them (Figure 2).

During all periods of measurement, breathing of the appropriate inspired air, counting from the head, and sampling of arterial and cerebral venous blood were begun simultaneously at the zero time for that period. The first pair of blood samples was drawn at a constant rate of $10 \mathrm{ml}$ per minute for the entire first minute to provide integrated values over that period. Thereafter, timed simultaneous arterial and venous blood samples of approximately $5 \mathrm{ml}$ each were drawn as rapidly as possible (approximately 10 seconds) at intervals of 1 to 1.5 minutes. Measurements during saturation lasted 10 minutes from the onset of breathing the $\mathrm{Kr}^{79}$ gas mixture; measurements during desaturation lasted 10 minutes from the onset of inhalation of room air following a 10 minute period of breathing the $\mathrm{Kr}^{7 \vartheta}$ gas mixture.

In order to test the ability of the method to detect changes in cerebral blood flow, several studies were performed during the infusion of $l$-norepinephrine, the breathing of 7 per cent $\mathrm{CO}_{3}$, or hyperventilation. These conditions were introduced only during the desaturation period after several minutes of resting control values had been obtained.

Blood oxygen and carbon dioxide contents were analyzed manometrically by the method of Van Slyke and Neill (6). Blood $\mathrm{pH}$ was determined anaerobically at ambient temperature by means of a glass electrode and Beckman Model $\mathrm{G}$ potentiometer and corrected to $37^{\circ} \mathrm{C}$ by the factors of Rosenthal (7). Blood $\mathrm{pCO}_{2}$ was calculated according to the nomogram of Peters and Van Slyke (8). Mean arterial blood pressure was measured by means of an air-damped mercury manometer connected to the femoral arterial manifold and adjusted to carotid artery level.

\section{RESULTS}

By means of the $\mathrm{Kr}^{\text {i9 }}$ method, it was possible to follow total cerebral blood flow minute by minute. In Table I are presented the results of 14 studies in 10 normal young men in which measurements were made continuously during steady state periods of approximately 10 minutes. Six of the studies were performed during saturation 
and eight during desaturation. During the first minute or two after the onset of saturation or desaturation, the quantity of $\mathrm{Kr}^{i 9}$ in the lungs is changing rapidly. Since it is enormously greater than the amount in the brain, even the small fraction of its scattered radiation which bypasses the lead shield significantly increases the rate of change of the head counting rate and leads to artifactually high values for cerebral blood flow. By the third minute, however, the lung $\mathrm{Kr}^{i 9}$ content is usually changing slowly and only negligibly influences the slope of the head counting curve. After the eighth minute, the head counting curve frequently becomes so flat and the arteriovenous difference so small that reading errors may greatly influence the calculated values for blood flow. Therefore, only the values between the third and eighth minutes were considered reliable and these are included in Table I. Over this period the minute-by-minute values for cerebral blood flow va- ried relatively little; the overall standard deviation within studies was equal to $\pm 72 \mathrm{ml}$ per minute or about \pm 6 per cent of the mean, and the variance within studies was significantly less than the variance between them $(p<0.001)$. The total mean of all 14 studies was $1,247 \mathrm{ml}$ per minute $(\mathrm{SD}= \pm 277)$. Mean cerebral blood flow in the ten subjects was $1,236 \mathrm{ml}$ per minute $(\mathrm{SD}= \pm$ 246). The results of saturation and desaturation studies were not significantly different. A slight but systematic upward drift of the values with time was observed in both the saturation and desaturation studies, but it was considerably more prominent in the former and may, perhaps, have resulted from $\mathrm{CO}_{2}$ accumulation in the dead space of the respiratory system.

The $\mathrm{Kr}^{79}$ and nitrous oxide methods were compared simultaneously in nine experiments in eight subjects; the inspired air mixture then contained 15 per cent $\mathrm{N}_{2} \mathrm{O}$ in addition to the $\mathrm{Kr}^{79}$,

TABLE I

Minute-to-minute cerebral blood flow in normal young adult men

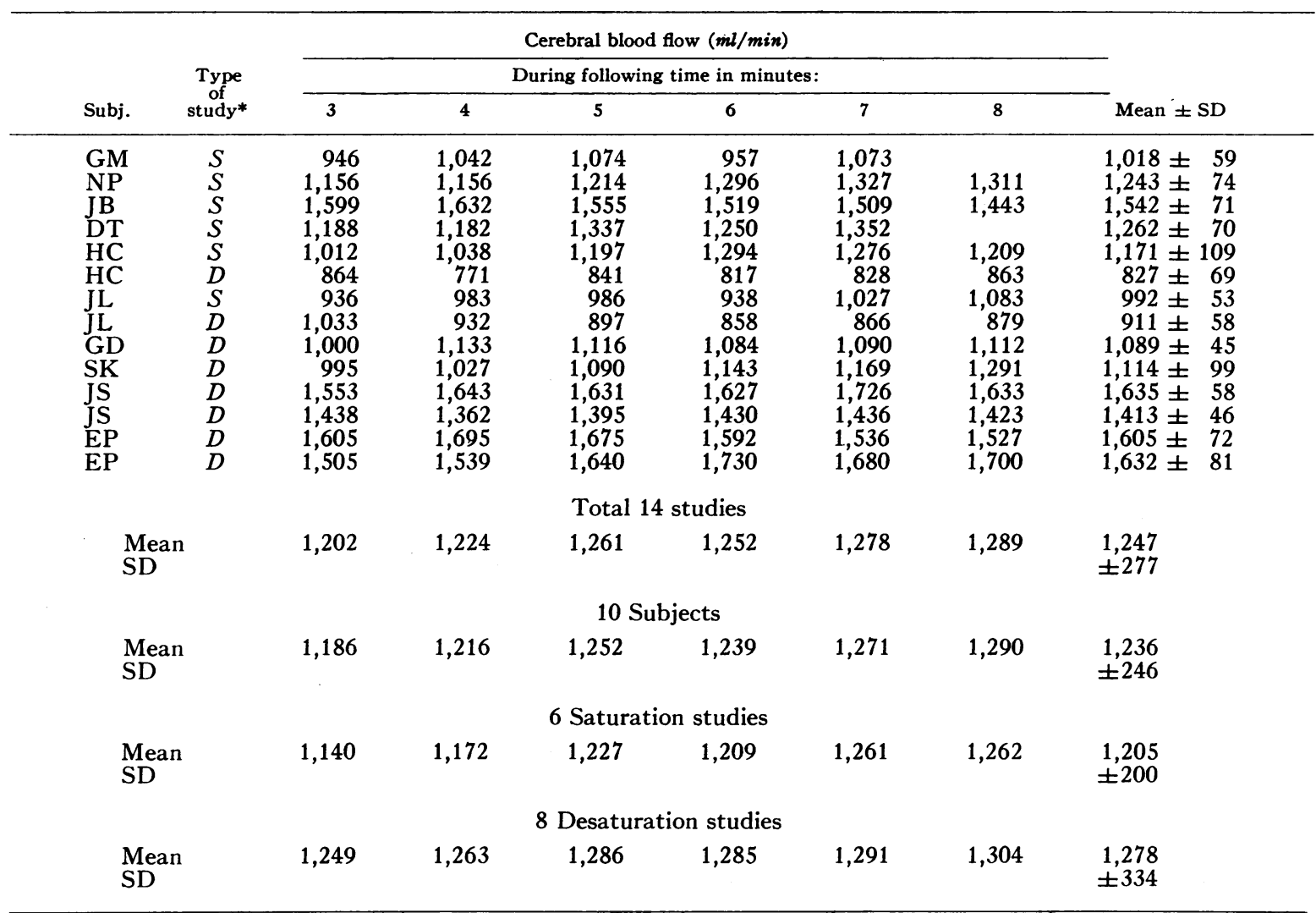

* $S=$ saturation, $D=$ desaturation. 
TABLE II

Comparative cerebral blood flow values calculated by indirect method from integrated cerebral arteriovenous $\mathrm{N}_{2} \mathrm{O}$ and $K r^{79}$ differences

\begin{tabular}{lcc}
\hline & \multicolumn{2}{c}{$\begin{array}{c}\text { Cerebral blood flow } \\
(\mathrm{ml} / 100 \mathrm{~g} / \mathrm{min})\end{array}$} \\
\cline { 2 - 3 } Subj. & $\mathrm{N}_{2} \mathrm{O}$ & $\mathrm{Kr}^{79}$ \\
GD & 55 & 66 \\
$\mathrm{HC}$ & 58 & 59 \\
$\mathrm{SK}$ & 56 & 60 \\
JL & 54 & 49 \\
JL & 51 & 50 \\
$\mathrm{GM}$ & 66 & 58 \\
$\mathrm{NP}$ & 48 & 48 \\
JB & 68 & 60 \\
DT & 62 & 65 \\
Mean & 57.5 & 57.3 \\
Mean overall diff. $\pm \mathrm{SD}=4.6 \pm 3.8$
\end{tabular}

and measurements were made during a steady state of at least ten minutes as required by the nitrous oxide technique (1). Cerebral blood flow was calculated in two ways: 1 ) indirectly from the integrated arteriovenous $\mathrm{N}_{2} \mathrm{O}$ difference over the entire ten minute period as described by Kety and Schmidt (1); and 2) indirectly from the integrated arteriovenous $\mathrm{Kr}^{79}$ difference exactly as with nitrous oxide. The brain: blood partition coefficient for krypton employed in the latter calculations was 1.06 , the average value found by
TABLE III

Comparison between the results of the $\mathrm{N}_{2} \mathrm{O}$ and direct $\mathrm{Kr}{ }^{79}$ methods for the determination of cerebral blood flow

\begin{tabular}{ccc}
\hline & \multicolumn{2}{c}{ Cerebral blood flow } \\
\cline { 2 - 3 } Subj. & $\begin{array}{c}\mathrm{N}_{2} \mathrm{O} \\
\text { method }\end{array}$ & $\begin{array}{c}\text { Direct } \mathrm{Kr}^{79} \\
\text { method }\end{array}$ \\
\hline & ml/100 $\mathrm{g} / \mathrm{min}$ & $\mathrm{ml} / 100 \mathrm{ml} / \mathrm{min}$ \\
HC & 58 & 86 \\
HC & $55^{*}$ & 60 \\
SK & 56 & 80 \\
JL & 54 & 69 \\
JL & 51 & 86 \\
JL & 51 & 63 \\
GM & $59^{*}$ & 71 \\
JP & 48 & 82 \\
DT & 68 & 99 \\
JS & 62 & 81 \\
JS & $58^{*}$ & 104 \\
EP & $58^{*}$ & 89 \\
EP & $57^{*}$ & 96 \\
Mean & 57.1 & 98 \\
SD & \pm 5.3 & $83.1 \dagger$ \\
Coefficient of correlation $=0.55(\mathrm{p}<0.05)$
\end{tabular}

* Calculated from integrated cerebral arteriovenous $\mathrm{Kr}^{79}$ differences by indirect method.

$\dagger$ Significantly different statistically as determined by method of paired comparison $(p<0.001)$.

Lassen and Munck (2) in subjects with normal hematocrits. Almost identical values for cerebral blood flow were obtained with both gases when calculated in this manner (Table II) ; there-

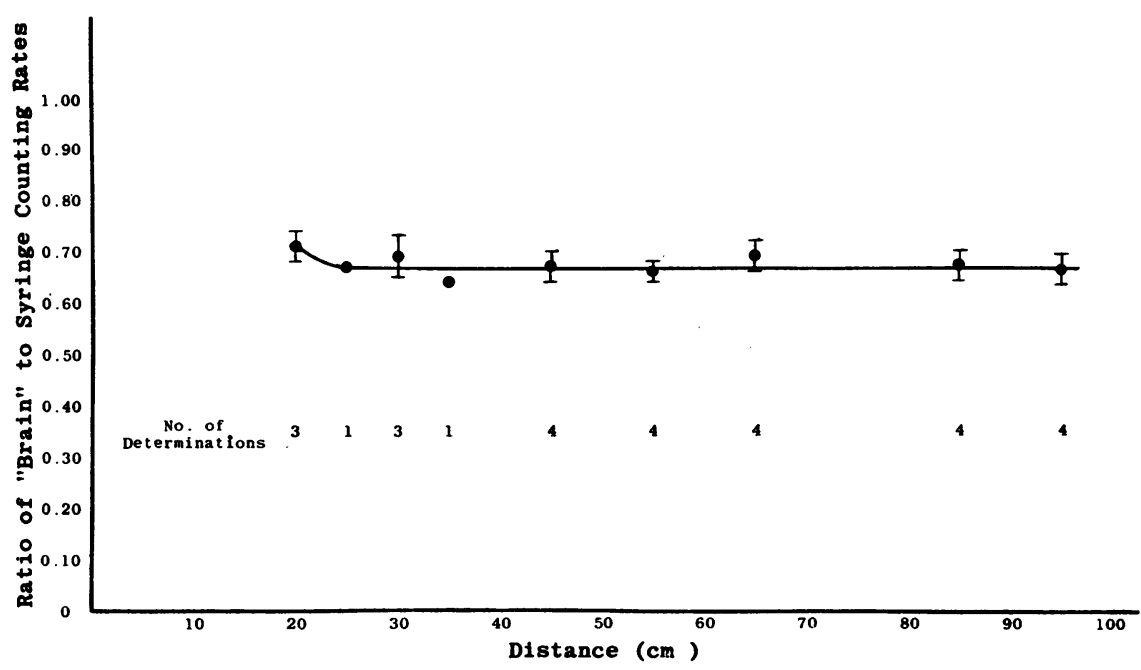

Fig. 3. Ratio of counting RAte From a Given QUANTity of $\mathrm{KR}^{79}$ Distributed THROUGHOUT SOLUTION IN "BRAIN" COMPARTMENT OF PLASTIC HEAD MODEL TO COUNTING RATE AT SAME DISTANCE FROM SAME QUANTITY OF $\mathrm{KR}^{\text {T9 }}$ CONCENTRATED IN 5 ML OF SOLUTION IN A 10 ML SYRINGE AS A FUNCTION OF DISTANCE BETWEEN THE MIDSAGITTAL PLANE OF THE HEAD OR THE MIDDLE OF THE SYRINGE AND THE PROXIMAL END OF THE SCINTILLATION CRYSTAL (SEE TEXT). 
fore, both methods were considered equally valid for comparison with the direct minute-to-minute method which was applied simultaneously in seven of the above experiments as well as in seven additional studies, including six in which $\mathrm{Kr}^{79}$ alone was employed. In order to compare the indirect method, which measures blood flow per $100 \mathrm{~g}$ of brain, taken as a whole, per minute, with the direct method, which yields total cerebral blood flow per minute, endocranial volume was calculated from extracranial measurements by the method of Lee and Pearson (9). No corrections were made for endocranial volume not occupied by the brain or for the specific gravity of the brain. The average of the minute-to-minute blood flow values between the third and eighth minutes per $100 \mathrm{ml}$ endocranial volume was then compared with the blood flow per $100 \mathrm{~g}$ brain per minute obtained by the indirect method over the entire ten minute period (Table III). The values obtained with the direct method uniformly exceeded those of the indirect technique (mean values equal $83.2 \mathrm{ml}$ per $100 \mathrm{ml}$ per minute and $56.9 \mathrm{ml}$ per $100 \mathrm{~g}$ per minute, respectively), but the correlation between them was statistically significant $(R=+0.55 ; \mathrm{p}<0.05)$.

In five studies cerebral blood flow was experimentally altered in the midst of the measurements to test the ability of the $\mathrm{Kr}^{79}$ method to detect and follow rapid changes. All measurements were made during desaturation, and the experimental conditions were imposed after a two minute control period. The studies included two on the effects of breathing 7 per cent $\mathrm{CO}_{2}$ and one each on the effects of hyperventilation of room air, hyperventilation of 100 per cent $\mathrm{O}_{2}$, and the intravenous infusion of $l$-norepinephrine at a rate of approximately $16 \mu \mathrm{g}$ per minute. The results

TABLE IV

Comparative changes in cerebral blood flow during various procedures as measured by direct $\mathrm{Kr}^{79}$ and $\mathrm{N}_{2} \mathrm{O}$ methods

\begin{tabular}{lccc}
\hline \hline \multicolumn{1}{c}{ Procedure } & \multicolumn{3}{c}{$\begin{array}{c}\text { Per cent change in } \\
\text { cerebral blood flow }\end{array}$} \\
\cline { 2 - 4 } & $\begin{array}{c}\mathrm{Kr}^{79} \\
\text { method }\end{array}$ & $\begin{array}{c}\mathrm{N}_{2} \mathrm{O} \text { method } \\
\text { (ref. no.) }\end{array}$ \\
\hline $\begin{array}{l}\text { Inhalation, } 7 \% \mathrm{CO}_{2} \\
\text { Hyperventilation, room air }\end{array}$ & +36 & +75 & $(10)$ \\
$\begin{array}{l}\text { Hyperventilation, 100\% } \mathrm{O}_{2} \\
l \text {-Norepinephrine infusion }\end{array}$ & -33 & -34 & $(10)$ \\
& -28 & -8 & $(11)$ \\
\hline
\end{tabular}

are graphically represented in Figure 4 and demonstrate the ability of the $\mathrm{Kr}^{i 9}$ method to follow continuous changes in cerebral blood flow. In Table IV are compared the maximum percentage changes in cerebral blood flow caused by these procedures with those previously observed in nitrous oxide method studies $(10,11)$. Although the experimental conditions cannot be compared precisely, the direct $\mathrm{Kr}^{\mathrm{i} 9}$ method appears to be at least as sensitive as the nitrous oxide technique and to yield proportionate results.

\section{DISCUSSION}

Total cerebral blood flow values obtained with the $\mathrm{Kr}^{79}$ method exceed those to be expected from the results of the nitrous oxide technique in a representative fraction of brain and the brain weight. This discrepancy is probably attributable to the collective effect of a number of factors. Although carefully shielded from the remainder of the body, the scintillation counter measuring brain $\mathrm{Kr}^{79}$ content must also detect radiation from the extracerebral tissues overlying the brain. Changes in $\mathrm{Kr}^{79}$ content of these tissues contribute to the slope of the head count curve and, therefore, also to the calculated values for cerebral blood flow. In order to evaluate the contribution from the overlying soft tissues, a tourniquet was applied to the head just above the ears, and the subject was allowed to breathe $\mathrm{Kr}^{79}$. After six minutes the tourniquet was released; despite a noticeable reactive hyperemia of the scalp, there was no significant change in the slope of the head count curve. These results indicate negligible contributions from the scalp probably because of its smaller volume and lower blood flow than the brain; the contribution from the skull remains unevaluated but is probably similar. The extracerebral tissues may, perhaps, account for some of the discrepancy between the $\mathrm{Kr}^{\text {} 9}$ and nitrous oxide methods but apparently do not obscure the measurement of changes in cerebral blood flow. For example, the directions and degrees of change elicited by hyperventilation and carbon dioxide inhalation are almost identical to those observed with the nitrous oxide technique (Table IV), despite the fact that these procedures cause opposite changes in extracerebral blood flow (12). 


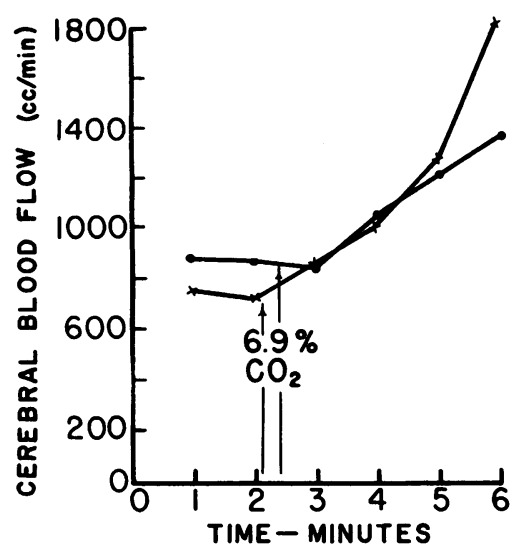

A

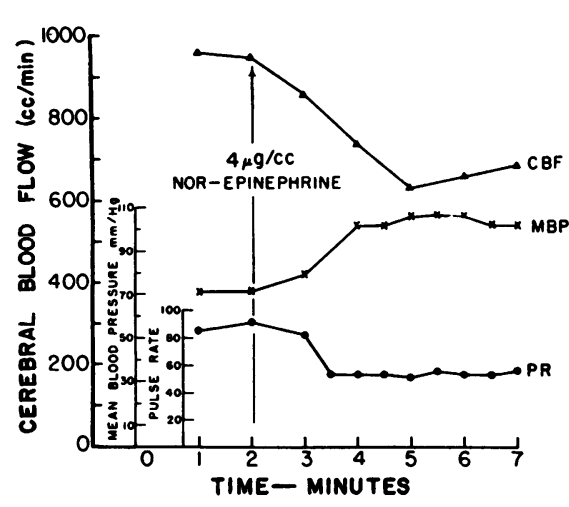

B

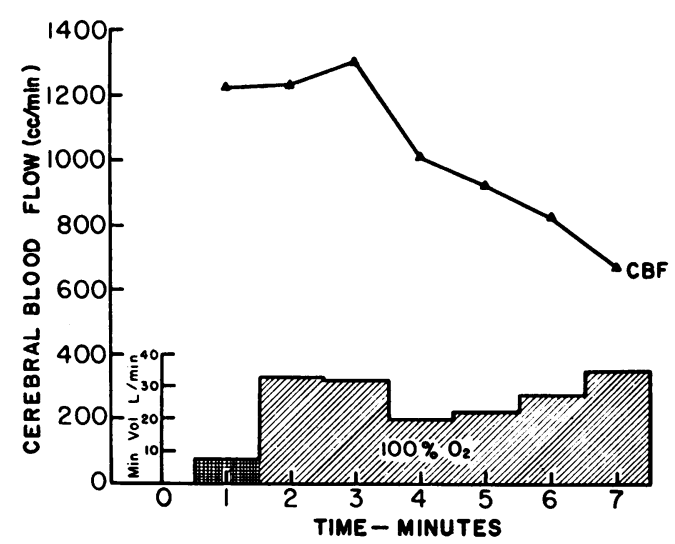

$\mathbf{C}$

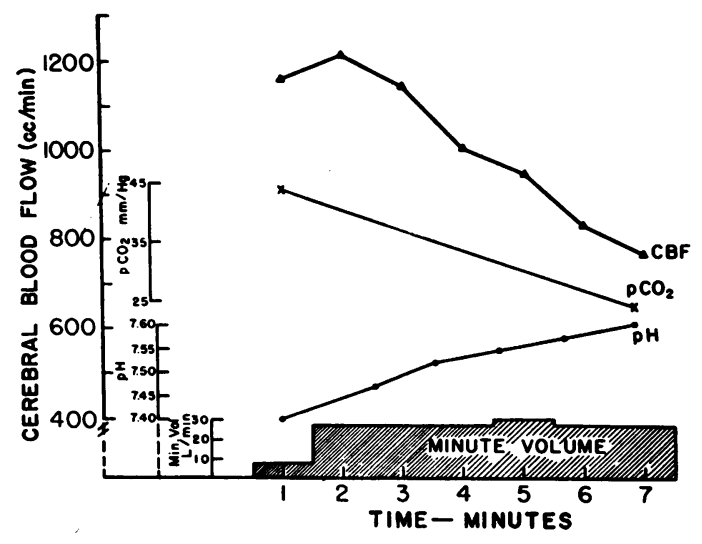

D

Fig. 4. Minute-to-minute values for CBF as Determined By the KR ${ }^{79}$ Method during EXPERIMENTALLY INDUCED CHANGES IN CEREBRAL BLOOD FLOW. A, two studies during the inhalation of 7 per cent $\mathrm{CO}_{2} ; \mathrm{B}$, during the continuous intravenous infusion of $4 \mu \mathrm{g}$ per $\mathrm{ml}$ $l$-norepinephrine solution at a rate of approximately $4 \mathrm{ml}$ per minute; $\mathrm{C}$, during hyperventilation of 100 per cent $\mathrm{O}_{2}$ at a rate of approximately $30 \mathrm{~L}$ per minute; $\mathrm{D}$, during hyperventilation of room air at a rate of approximately $30 \mathrm{~L}$ per minute.

Rapid changes in the $\mathrm{Kr}^{79}$ content of the lungs and respiratory passages also influence the slope of the head count curve. This effect arises partly, perhaps, from incompletely shielded paranasal sinuses but mainly from scattered radiation from the chest. Although both sources represent a very small fraction of the radioactivity in the respiratory system, they may still be significant compared to the quantity in the brain because of the low tissue: gas partition coefficient (approximately 0.05 ) of krypton (13). As previously noted, this effect is sufficient to invalidate measurements made during the first and often second minutes of saturation or desaturation and may also contribute a little to the excessively high values for cerebral blood flow observed in subsequent minutes. In one experiment a continuous record of chest radioactivity was made throughout the procedure, and its effect on the head counts was calculated by means of a "scattering" factor determined in experiments with "phantom lungs." It was found to increase the calculated value for cerebral blood flow during the three to eight minute period by 3.5 per cent.

The greatest single cause of the high values obtained with the $\mathrm{Kr}^{\text {i9 }}$ method is probably the disproportionate weighting of different areas of the brain in the total head count. The overall 
linear absorption coefficient for $\mathrm{Kr}^{i 9} \gamma$-radiation in brain tissue was measured and found to be approximately $0.09 \mathrm{~cm}^{-1}$ (one-half thickness $=8$ $\mathrm{cm})$; there is, therefore, significant self-absorption of the $\gamma$-radiation within the brain. Because of this effect as well as the inverse square law, the $\mathrm{Kr}^{\text {i9 }}$ content in the cerebral tissues becomes progressively less represented in the total head counting rate in going from the surface of the brain closest to the counter to the other side. It has been estimated on the basis of theoretical considerations that, even with uniform $\mathrm{Kr}^{\text {i9 }}$ concentration throughout the brain, the most proximal $1 \mathrm{~cm}$ thickness of brain tissue would alone account for at least 18 per cent of the total counting rate or three times the amount to be expected if all areas were equally represented. Since the most superficial and, therefore, most efficiently represented areas contain disproportionately high amounts of gray matter compared to the brain as a whole, the head counting rate is excessively weighted in favor of the cerebral cortical tissues which have considerably higher rates of blood flow than most other areas of the brain (14). This effect undoubtedly accounts for much of the discrepancy between the results of the $\mathrm{Kr}^{\text {i9 }}$ and $\mathrm{N}_{2} \mathrm{O}$ methods; it may also render the method susceptible to errors arising from the redistribution of blood flow between the deep and superficial areas of the brain.

Despite its defects, the $\mathrm{Kr}^{i 9}$ method performs quite well in studies of functions not otherwise measurable in man. It permits the estimation of cerebral blood flow under nonsteady state conditions and, as illustrated in Figure 4, is capable of following rapid or transient changes in this function. Although its descriptions of these changes may not be quantitatively accurate, they are indicative of and probably proportional to those actually occurring in the brain. It does not require the assumption of a constant cerebral metabolic rate as does the arteriovenous $\mathrm{O}_{2}$ difference method which can also be used for the detection of rapid changes in cerebral blood flow (15). In fact, when combined with arteriovenous $\mathrm{O}_{2}$ differences, the $\mathrm{Kr}^{79}$ method can be employed to follow changes in cerebral metabolic rate as well.

Many of the problems encountered in the development of the $\mathrm{Kr}^{79}$ method are specifically re- lated to the tracer substance and the form in which it was administered. A nongaseous substance which fulfilled the necessary requirements and which could be injected intravenously would obviate the influence of the isotope in the lungs, air passages and paranasal sinuses with considerable simplification of the problem of shielding. Antipyrine iodinated with $\mathrm{I}^{131}$ has been shown (16) to cross the blood-brain barrier rapidly and to have a distribution coefficient between brain and blood of approximately unity (17); it appears to have certain advantages with respect to this method which warrant further investigation.

\section{SUM MARY}

1. A method for the rapid continuous estimation of total cerebral blood flow in man by means of radioactive krypton $\left(\mathrm{Kr}^{i 9}\right)$ is presented; its theoretical basis, developmental experiments, and procedure are described.

2. Mean total cerebral blood flow in ten normal young men was $1,236(\mathrm{SD}= \pm 246)$; the standard deviation among minute-to-minute values within studies was $\pm 72 \mathrm{ml}$ per minute or about 6 per cent of the mean value.

3. Cerebral blood flow determined by the $\mathrm{Kr}^{79}$ method and corrected for intracranial volume was found to be significantly higher than the values obtained simultaneously with the nitrous oxide method; in 14 experiments the mean values were $83 \mathrm{ml}$ per $100 \mathrm{ml}$ intracranial volume per minute and $57 \mathrm{ml}$ per $100 \mathrm{~g}$ brain tissue per minute, respectively. The results of the two methods were, however, significantly correlated $(\mathrm{R}=+0.55$; $\mathrm{p}<0.05)$.

4. Sources of error in the $\mathrm{Kr}^{i 9}$ method are evaluated, and the causes of the discrepancy between the results of the nitrous oxide and $\mathrm{Kr}^{79}$ methods are discussed.

5. The $\mathrm{Kr}^{79}$ method was found capable of following rapid changes in cerebral blood flow such as, for example, those induced by hyperventilation, $\mathrm{CO}_{2}$ inhalation, or $l$-norepinephrine infusion.

\section{ACKNOWLEGMENTS}

The authors wish to express their gratitude to Dr. Sherman Frankel and Dr. Wilton M. Krogman for valuable advice and suggestions, and to Mr. Gerald B. Pidcock, Mr. John Bowanko and Miss Phyllis Campbell for outstanding technical assistance. 


\section{REFERENCES}

1. Kety, S. S., and Schmidt, C. F. The nitrous oxide method for the quantitative determination of cerebral blood flow in man: Theory, procedure and normal values. J. clin. Invest. 1948, 27, 476.

2. Lassen, N. A., and Munck, O. The cerebral blood flow in man determined by the use of radioactive krypton. Acta physiol. scand. 1955, 33, 30.

3. Hollander, J. M., Perlman, I., and Seaborg, G. T. Table of isotopes. Rev. mod. Phys. 1953, 25, 469.

4. Thulin, S. Studies in nuclear spectroscopy with electromagnetically separated gaseous isotopes. II. Ark. Fysik 1955, 9, 137.

5. Wechsler, R. L. Effects of acceleration upon cerebral metabolism and cerebral blood flow. Phase I. Development of a new method for continuous measurement of cerebral blood flow in humans under acceleration. U. S. Naval Air Development Center, Aviation Medical Acceleration Laboratory, Johnsville, Pa., Aug. 1952, Report no. NADC-NA-5202.

6. Van Slyke, D. D., and Neill, J. M. The determination of gases in blood and other solutions by vacuum extraction and manometric measurement. J. biol. Chem. 1924, 61, 523.

7. Rosenthal, T. B. The effect of temperature on the $\mathrm{pH}$ of blood and plasma in vitro. J. biol. Chem. 1948, 173, 25.

8. Peters, J. P., and Van Slyke, D. D. Quantitative Clinical Chemistry. Methods. Baltimore, Williams and Wilkins, 1932, vol. II.

9. Lee, A., and Pearson, K.-V. Data for the problem of evolution in man.-VI. A first study of the cor- relation of the human skull. Phil. Trans. A 1901, 196, 225.

10. Kety, S. S., and Schmidt, C. F. The effects of altered arterial tensions of carbon dioxide and oxygen on cerebral blood flow and cerebral oxygen consumption of normal young men. $J$. clin. Invest. 1948, 27, 484.

11. King, B. D., Sokoloff, L., and Wechsler, R. L. The effects of $l$-epinephrine and $l$-nor-epinephrine upon cerebral circulation and metabolism in man. $\mathrm{J}$. clin. Invest. 1952, 31, 273.

12. Schmidt, C. F., and Hendrix, J. P. The action of chemical substances on cerebral blood vessels. Res. Publ. Ass. nerv. ment. Dis. 1937, 18, 229.

13. Lawrence, J. H., Loomis, W. F., Tobias, C. A., and Turpin, F. H. Preliminary observations on the narcotic effect of xenon with a review of values for solubilities of gases in water and oils. J. Physiol. 1946, 105, 197.

14. Landau, W. M., Freygang, W. H., Jr., Rowland, L. P., Sokoloff, L., and Kety, S. S. The local circulation of the living brain; values in the unanesthetized and anesthetized cat. Trans. Amer. neurol. Ass. 1955, 80, 125.

15. Patterson, J. L., Jr., and Cannon, J. L. Postural changes in the cerebral circulation, studied by continuous oximetric and pressure-recording techniques (abstract). J. clin. Invest. 1951, 30, 664.

16. Sapirstein, L. A., and Hanusek, G. E. Cerebral blood flow in the rat. Amer. J. Physiol. 1958, 193, 272.

17. Hansen, D. B. Unpublished studies.

\section{SPECIAL NOTICE TO SUBSCRIBERS}

Post Offices will no longer forward the Journal when you move. Please notify The Journal of Clinical Investigation, Business Office, 333 Cedar Street, New Haven 11, Conn., at once when you have a change of address, and do not omit the zone number if there is one. 